\title{
PEMBANGUNAN FLASH CARD BERBASIS AUGMENTED REALITY UNTUK MENUNJANG PEMBELAJARAN PADA ANAK PRA SEKOLAH
}

\author{
Abdullah Azzam, Faisal R. M, Muhammad Ridwan A. P \\ Program Pasca Sarjana Magister Teknik Industri, \\ Fakultas Teknologi Industri,Universitas Islam Indonesia \\ Jalan Kaliurang Km. 14,5 Sleman, Yogyakarta 55184
}

\begin{abstract}
Teaching and learning activities at an early age children is important to note especially about learning media used. In the learning process often children do not focus on what is being taught by the teacher because there is nothing more exciting than being taught by the teacher. In addition the level of boredom child will be increased when the media is not interesting again. Great Media affect the child's motivation to learn. The use of technology in learning media is expected to increase the learn motivation in early childhood. This research will be built a learning media such as flash card that uses augmented reality technology that is expected to increase the learn motivation of early childhood. The results showed that the use of flash media cards augmented reality can improve learning outcomes in children seen from the responses given by children when study. Sistem flash cards augmented reality can be run properly and children can use them independently.
\end{abstract}

Keywords :Focus, Motivation, Media, Flash Card, Augmented Reality.

\section{LATAR BELAKANG}

Penggunaan teknologi informasi dan komunikasi dalam proses belajar mengajar siswa pra sekolah saat ini membutuhkan eksplorasi lebih lanjut. Eksplorasi ini bertujuan untuk memberikan kontribusi pemahaman yang lebih baik terhadap anak dalam proses belajar. Penggunaan teknologi informasi merupakan salah satu cara agar anak dapat dengan mudah memahami apa yang sedang dipelajari. Disamping itu, penggunaan teknologi dalam pendidikan dapat menciptakan lingkungan pendidikan yang baru, mengubah hubungan antara pengajar dan siswa yang masih bersifat tradisional, dan dapat meningkatkan kualitas pendidikan. Oleh karena itu, teknologi dapat dianggap sebagai "alat yang berpotensi untuk memberikan perubahan dalam pendidikan" (Tezci, 2009). Ada beberapa teknologi informasi yang dapat digunakan dalam menunjang proses belajar anak, salah satu diantaranya yaitu teknologi Augmented reality (AR).

Pada proses belajar mengajar siswa pra sekolah seringkali anak tidak fokus pada apa yang sedang diajarkan oleh guru karena ada hal yang lebih menarik dari yang sedang diajarkan oleh guru. Maka diperlukan sebuah media yang atraktif dan inovatif sehingga anak dapat lebih fokus terhadap hal yang sedang diajarkan oleh guru. Ada beberapa alat bantu yang digunakan sehingga siswa dapat memahami dan fokus terhadap apa yang diajarkan oleh guru. Salah satu media tersebut adalah flash card. Media ini sudah cukup membantu siswa dalam belajar, misalnya dalam belajar kosakata seperti membaca dan menulis serta memahami huruf demi huruf dan pengenalan beberapa objek dalam media flash card tersebut. Dalam hal ini teknologi AR memungkinkan membuat flash card tersebut menjadi lebih baik sehingga siswa lebih fokus dan termotivasi dalam belajar. Pada penelitian ini penulis mencoba untuk membangun sebuah sistem flash card AR (FCAR) sehingga siswa dapat 
lebih fokus dan termotivasi dalam proses belajar.

\section{RUMUSAN MASALAH}

Berdasarkan uraian latar belakang diatas maka perumusan masalah pada proposal penelitian ini adalah bagaimana sistem FCAR yang dapat memotivasi anak usia dini pada proses belajar mengajar?

\section{TINJAUAN PUSTAKA}

\subsection{Augmented Reality}

AR adalah sistem yang mencitrakan gambar tiga dimensi yang seolah nyata. Proses ini bisa dibagi menjadi beberapa tahapan dan komponen. Untuk mencitrakan gambar tiga dimensi tersebut, sistem AR terlebih dahulu harus melakukan penglihatan atau vision terhadap lingkungan yang padanya akan dicitrakan obyek virtual. Kemudian melakukan proses tracking terhadap obyek spesifik yang menentukan letak citraan obyek virtual tersebut. Obyek tersebut akan dikenali dan dianalisis posisi dan orientasinya sehingga komputer dapat melakukan proses pencitraan obyek yang akan tampak pada perlengkapan display.

\subsection{Mobile Device Augmented reality}

Pada umumnya AR yang menggunakan mobile device sebagai alat bantu bekerja dengan tahapan sebagai berikut :

a. Subyek menggunakan mobile device (misalnya smartphone), yang kemudian digunakan untuk melihat dunia fisik melalui lensa atau kamera tertentu.

b. Mobile device akan melakukan identifikasi terhadap obyek dunia fisik dan informasi akan diterima kembali.

c. Informasi kemudian dikirim ke sumber data.

d. Informasi spesifik akan dikirimkan kembali ke mobile device.

e. Mobile device yang digunakan untuk melihat dunia fisik kini telah dilengkapi informasi tentang obyek yang dilihat.

f. Subyek melihat dunia yang berbedabeda melalui "pengelihatan" mobile device, tergantung jenis informasi yang mereka inginkan.

\section{KAJIAN INDUKTIF}

Cascales et al. (2013) meneliti tentang pengaruh penggunaan teknologi AR pada siswa pra sekolah dan penerimaan orang tua terhadap penggunaan teknologi tersebut, dengan menganalisis data yang dikumpulkan melalui wawancara dengan orang tua. Penelitian ini berdasarkan pada beberapa komponen yaitu motivasi, pengetahuan, membaca dan menulis, kreativitas dan tingkat kepuasan. Menurut orang tua, penelitian menunjukan bahwa ada banyak manfaat dalam menggunakan teknologi AR dilihat dari pengintegrasian beberapa komponen dalam rangka mencapai tujuan bersama.

Parhizkar et al. (2011) meneliti tentang adanya tingkat kebosanan yang cukup tinggi pada saat anak-anak membaca dengan cara tradisional, sedangkan ada begitu banyak hiburan diluar sana yang jauh lebih menarik daripada membaca (menurut wawancara seorang guru pendidikan). Oleh karena itu, guru harus mengeluarkan ide-ide yang menarik perhatian anak agar mendorong mereka untuk terbiasa membaca. Anak-anak belajar lebih cepat jika mereka dapat berinteraksi dengan obyek atau bahkan memainkan dalam cerita. Jadi sangat penting untuk mendorong anak-anak untuk membaca dan peneliti percaya bahwa lebih muda anak mulai menerima pendidikan, lebih cepat dan lebih baik anak dapat menyerap pengetahuan. Dan teknologi AR digunakan oleh peneliti sebagai media teknologi untuk mendorong anak dalam membaca.

Nincarean et al. (2013) meneliti tentang pengadopsian teknologi augmented reality dan mobile augmented reality dalam dunia pendidikan untuk menambah pengalaman belajar siswa. Pada penelitian yang mereka lakukan, siswa sama sekali belum pernah mencoba mobile augmented reality, dan dari hasil penelitian siswa merasa termotivasi dan menikmati serta menimbulkan efek positif. 
Zarzuela et al. (2013) melakukan penelitian tentang pembuatan game augmented reality untuk anak-anak dan orang cacat. Aplikasi game ini berlatarkan kebun binatang dimana pengguna dapat menambah pengetahuan tentang topik tertentu, dalam kasus ini adalah hewan. Pengguna dapat berinteraksi dengan elemenelemen dan adegan tertentu pada game tersebut menggunakan ponsel layar sentuh. Ini merupakan cara baru untuk belajar tentang berbagai jenis binatang yang hidup dikebun binatang. Hasil dari penelitian ini adalah dimana kelompok anak-anak yang bermain game tersebut berhasil mempelajari pertanyaan dan jawaban tentang hewanhewan. Beberapa setelah bermain aplikasi, anak-anak tetap bias menjawab pertanyaan tentang hewan. Hal ini merupakan cara yang baik dan menarik untuk memberikan pengetahuan jangka panjang kepada anakanak tentang binatang.

Santana-Mancilla et al. (2012) melakukan penelitian tentang pembuatan sebuah sistem augmented reality mobile yang memungkinkan siswa di meksiko untuk mengakses konten-konten tambahan yang berkaitan dengan teks buku mereka. Sistem ini dibuat dengan mencetak gambar-gambar dalam buku sebagai bagian dari topik yang diajarkan dan menunjukan konten multimedia yang melengkapi topik yang dibahas dalam buku. Hasil dari penelitian ini menunjukan bahwa $97 \%$ pengguna puas dengan sistem yang telah dibuat.

\section{KASUS DAN MODEL}

Untuk mengetahui aktifitas yang dilakukan user secara detail maka diperlukan DFD level 0 untuk menjelaskan aktifitas user dalam menggunakan aplikasi FCAR. DFD level 0 dari sistem FCAR ditunjukkan pada gambar 1 berikut ini :

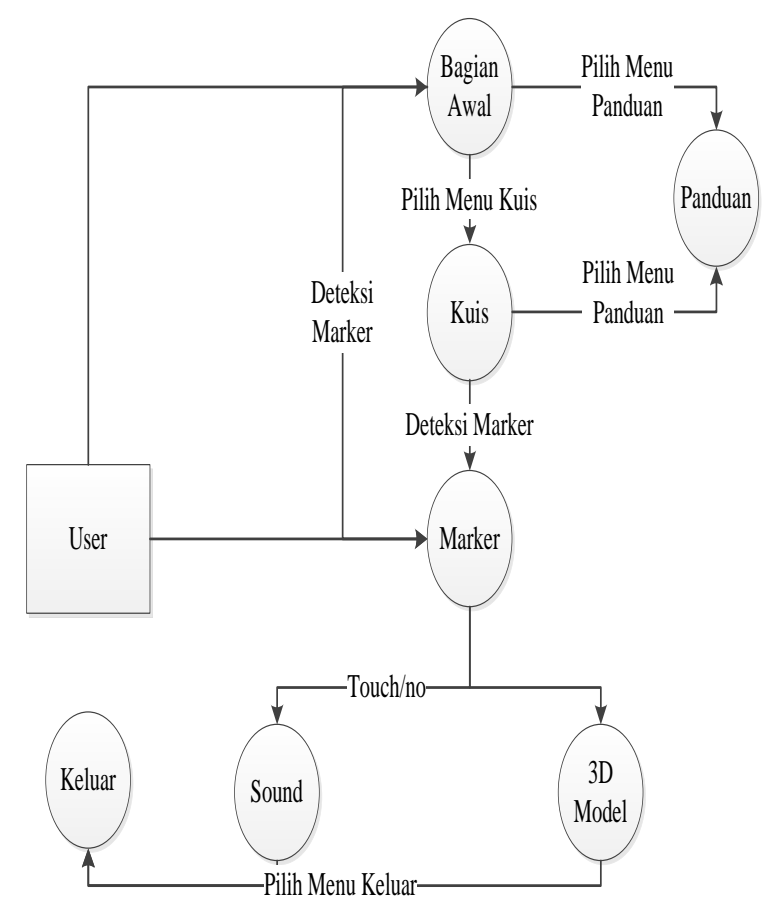

Gambar 1. DFD Sistem FCAR

DFD level 0 tersebut menjelaskan bahwa langkah awal user yaitu menjalankan aplikasi FCAR. User akan melihat bagian awal dari aplikasi yang akan menampilkan panduan untuk menjalankan bagian awal tersebut. Pada bagian awal juga terdapat menu-menu berupa button yang akan menghubungkan user ke aktifitas lain yaitu menu kuis, panduan dan keluar. Menu kuis akan menghubungkan pada bagian kuis, menu panduan akan membuka panduan, dan menu keluar akan menghentikan aplikasi.

Setelah membuka aplikasi user diharuskan mengatur posisi marker dan mengarahkan kamera smartphone untuk melakukan deteksi marker. Marker akan terdeteksi sehingga dapat memunculkan model 3D dan suara. Suara dapat dimainkan langsung oleh user atau user harus menyentuh bagian dari marker untuk memainkan suara. Bagian awal dan akhir hanya berbeda pada pengaturan posisi marker. Pada bagian kuis user diharuskan menggabungkan beberapa marker menjadi marker baru untuk kemudian dapat terdeteksi oleh kamera smartphone dan mengeluarkan model 3 dimensi dan suara. 


\subsection{Rancangan Elemen Sistem}

Elemen-elemen yang dibutuhkan dalam sistem yaitu flash card (marker), model 3 dimensi dan suara. Untuk merancang elemen-elemen tersebut dibutuhkan data yang mendukung sesuai dengan kebutuhan sistem. Pada sistem FCAR user utamanya adalah anak-anak, sehingga sistem didesain sesuai dengan apa yang disukai oleh anakanak. Oleh karena itu data-data pendukung untuk mendesain elemen-elemen sistem diambil dari anak-anak. Data yang telah dikumpulkan akan dijumlah sesuai dengan konten yang ada pada tiap kuisioner. Hasil kuisioner I adalah anak-anak yang menyukai atau memilih obyek real sebanyak 88 anak dan yang memilih obyek kartun sebanyak 67 anak. Sehingga obyek 3D yang digunakan pada FCAR adalah obyek real.

Hasil kisioner II adalah bentuk flash card yang paling banyak disukai anak-anak adalah flash card no 1,sedangkan suara yang paling banyak disukai adalah suara guru. Untuk warna background dipilih 3 warna terbanyak disukai oleh anak-anak. Pemilihan warna juga menyesuaikan tingkat sensitifitas dari deteksi marker. Jika tingkat sensitifitas rendah maka akan dipilih warna lain sesuai dengan tingkatan yang paling banyak disukai oleh anak-anak.

Dari hasil rekap data kuisioner diatas maka desain flash card yang sesuai dengan kesukaan anak-anak seperti pada Gambar 2 dibawah ini:

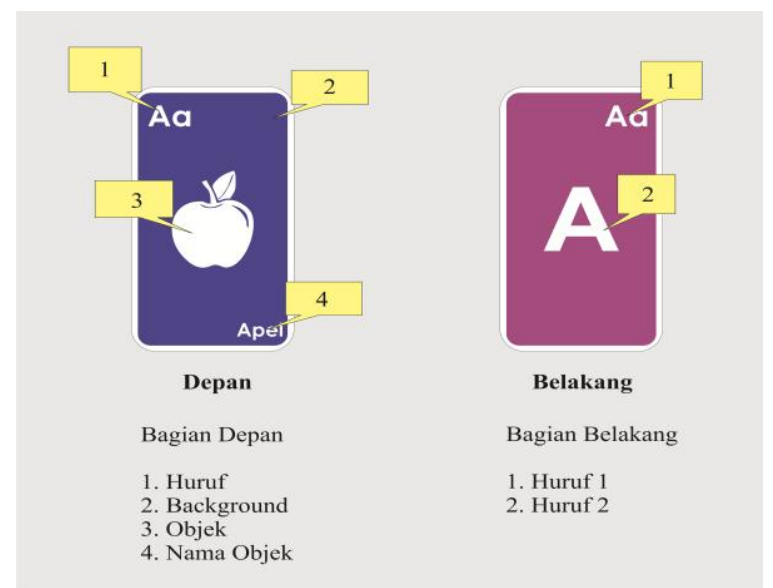

Gambar 2. Rancangan Akhir Flash Card.
Desain flash card yang digunakan terdiri dari dua bagian, yaitu bagian depan dan bagian belakang. Pada bagian depan terdapat beberapa konten yaitu :

a. Huruf

Konten huruf ini menunjukkan jenisjenis huruf dari huruf a-z. Konten huruf ini menunjukan huruf besar dan huruf kecil. Di harapkan siswa dapat mengenal jenis-jenis huruf dengan baik dan benar.

b. Background

Background digunakan untuk mempercantik flash card. Pemilihan warna yang disukai oleh anak-anak dapat menambah daya tarik anak-anak untuk belajar.

c. Obyek

Konten obyek digunakan untuk menunjukan bentuk-bentuk obyek yang akan diajarkan kepada anak-anak. Desain obyek menggunakan bentuk siluet sehingga hanya menunjukkan bentuk secara dari obyek tersebut. Sedangkan bentuk detail dari objek tersebut akan ditunjukan dengan bentuk tiga dimensi menggunakan teknologi AR. Penggunaan bentuk siluet diharapkan anak-anak dapat mengenali obyek hanya dengan melihat bentuknya.

d. Nama Obyek

Nama obyek digunakan untuk menunjukan nama dari obyek yang akan diajarkan oleh anak-anak.

Pada bagian belakang terdiri dari huruf 1 dan huruf 2. Huruf 1 terdiri dari huruf besar dan huruf kecil sedangkan huruf 2 hanya menunjukan huruf besar saja. Bagian belakang dari flash card digunakan untuk menguji kemampuan psikomotorik dari anak dengan menyusun huruf-huruf membentuk kata yang menunjukan nama dari suatu obyek.

Register Marker (Flash card) Register marker dilakukan sebelum membuat user interface untuk sistem AR secara online. Setelah user meng-upload flash card yang sekaligus digunakan sebagai marker maka 
akan menghasil rating. Setiap marker Hasil rating yang didapat kan pada setiap memiliki tingkatan rating yang berbeda. marker ditunjukkan pada Tabel 1 berikut ini :

Tabel 1. Rating Marker

\begin{tabular}{llcllcllc}
\hline No & $\begin{array}{c}\text { Nama } \\
\text { Marker }\end{array}$ & Rating & No & $\begin{array}{c}\text { Nama } \\
\text { Marker }\end{array}$ & Rating & No & $\begin{array}{c}\text { Nama } \\
\text { Marker }\end{array}$ & Rating \\
\hline 1 & Jeruk & 3 & 24 & Ayam & 5 & 47 & Rusa & 4 \\
2 & Unta & 4 & 25 & Zebra & 4 & 48 & Obor & 5 \\
3 & Jangkrik & 4 & 26 & Vas & 5 & 49 & Hamster & 4 \\
4 & Awan & 5 & 27 & Ular & 5 & 50 & Donat & 5 \\
5 & xantus & 4 & 28 & Truk & 4 & 51 & Dadu & 4 \\
6 & sapi & 4 & 29 & Topi & 3 & 52 & Yoyo & 3 \\
7 & quokka & 4 & 30 & Semut & 5 & 53 & Onta & 5 \\
8 & panda & 5 & 31 & Palu & 3 & 54 & Lilin & 3 \\
9 & nyamuk & 4 & 32 & Meja & 4 & 55 & Itik & 3 \\
10 & nuri & 2 & 33 & Mobil & 4 & 56 & Flaminggo & 4 \\
11 & nanas & 5 & 34 & Lampu & 5 & 57 & Dompet & 4 \\
12 & lebah & 4 & 35 & Kuda & 4 & 58 & Cicak & 5 \\
13 & gelas & 4 & 36 & Katak & 4 & 59 & Capung & 4 \\
14 & wortel & 4 & 37 & Jerapah & 2 & 60 & Bebek & 4 \\
15 & Sofa & 3 & 38 & Ikan & 2 & 61 & Bola & 4 \\
16 & Rumah & 5 & 39 & Harimau & 4 & 62 & Apel & 3 \\
17 & Pinguin & 4 & 40 & Garpu & 3 & 63 & Gajah & 5 \\
18 & Cabai & 4 & 41 & Ember & 3 & & & \\
19 & Roda & 5 & 42 & Buku & 4 & & & \\
20 & Mawar & 4 & 43 & Zaitun & 5 & & & \\
21 & Obeng & 5 & 44 & Wader & 3 & & & \\
22 & Kupu & 4 & 45 & Udang & 5 & & & \\
23 & Elang & 5 & 46 & Tikus & 3 & & & \\
\hline
\end{tabular}

Tabel 1 menunjukkan bahwa rating setiap marker sudah memenuhi kriteria yaitu rating bernilai diantara 2-5. Maka marker dapat di download untuk selanjutnya dapat digunakan dalam aplikasi FCAR.

\subsection{Desain Model 3 Dimensi (3D)}

Sesuai dengan hasil dari pengumpulan data, model yang paling disukai oleh anakanak adalah model yang real. Sehingga dalam tahap ini peneliti mendesain model yang akan ditampilkan menggunakan software $3 d$ s max dengan tampilan real.

Sistem augmented reality menggunakan smartphone untuk menampilkan $3 \mathrm{~d}$ model, maka model 3D yang dibuat harus menyusaikan kebutuhan smartphone yaitu model 3D dengan spesifikasi low poly agar model 3D yang ditampilkan menggunakan smartphone tidak terlalu berat. Maka model
3D yang disesain tidak benar-benar real, namun model 3D yang mendekati real. Contoh model 3D yang telah didesain menggunakan $3 d s$ Max, ditunjukkan pada Gambar 3 dibawah ini:

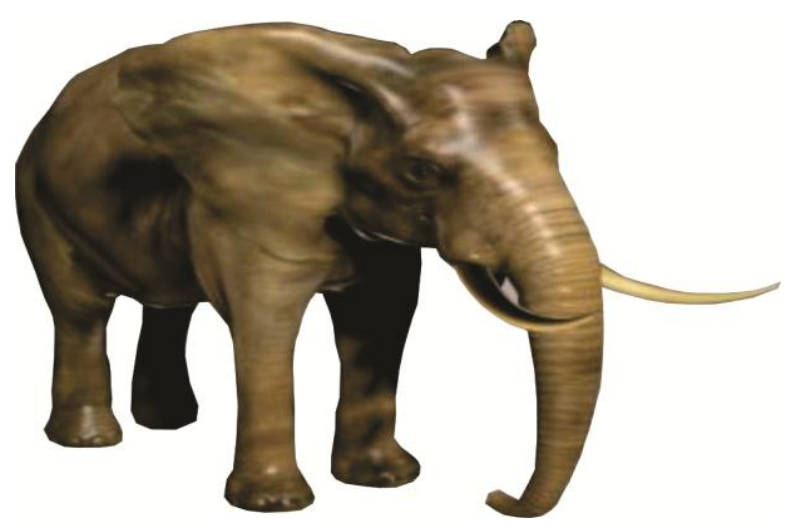

Gambar 3. Desain Model 3D. 


\subsection{User Interface}

Aplikasi FCAR terdiri dari dua bagian yaitu bagian awal dan akhir. Pada tiap bagian terdapat menu-menu sebagai penghubung antar bagian atau untuk melakukan aktivitas lainnya. Beberapa fungsi yang ada di bagian awal ini adalah :

a. Panduan

Panduan berfungsi untuk menampilkan tutorial penggunaan sistem FCAR kepada user agar user dapat mengetahui cara menggunakan sistem dengan baik dan benar. Panduan ini dibuat menggunakan tool yang ada didalam unity yaitu dengan tool panel dan text.

\section{b. Button}

Ada 3 button yang diletakkan sejajar dibagian atas layout yaitu button kuis untuk menuju ke bagian kuis, button panduan untuk menampilkan panduan, button keluar untuk keluar dari aplikasi. Button dibuat dengan tool button yang sudah tersedia di unity dan mengatur inspector button seperti warna, panjang, tinggi, letak button dan text.

Button berfungsi untuk menghubungkan scan satu dengan yang lainnya. Button tidak akan berfungsi jika tidak menggunakan kode pemrograman untuk menjalankan fungsinya. Dalam hal button bahasa pemrograman yang digunakan adalah C\#. Pada Gambar 4 dibawah ini menunjukkan kode bayangan untuk menjalankan fungsi pada button.

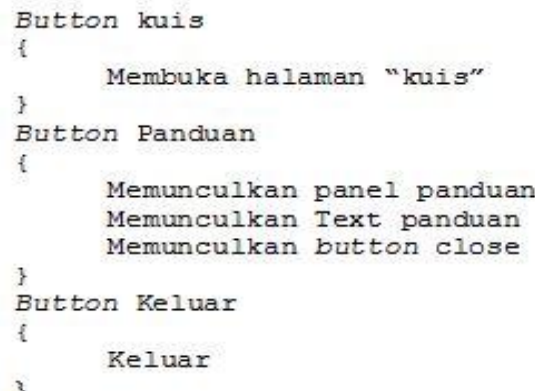

Gambar 4. Kode Bayangan Button.

\subsection{Augmented Reality}

Pada bagian awal ini terdapat sistem AR yang berfungsi untuk menampilkan model 3D dari flash card yang sudah di buat dan didaftarkan sebelumnya. Berikut langkahlangkah pembuatan AR dan hasil AR yang ditunjukkan pada Gambar 5 :

1. Input SDK Vuforia ke Unity.

2. Input marker (flash card) ke Unity.

3. Atur image target.

4. Pilih marker pada image target.

5. Atur kamera.

6. Input $3 \mathrm{~d}$ model yang sesuai dengan marker ke Unity.

7. Posisikan 3D model tepat diatas marker.

8. Posisikan camera agar dapat mengcapture marker dan 3D Model.

\section{Build.}

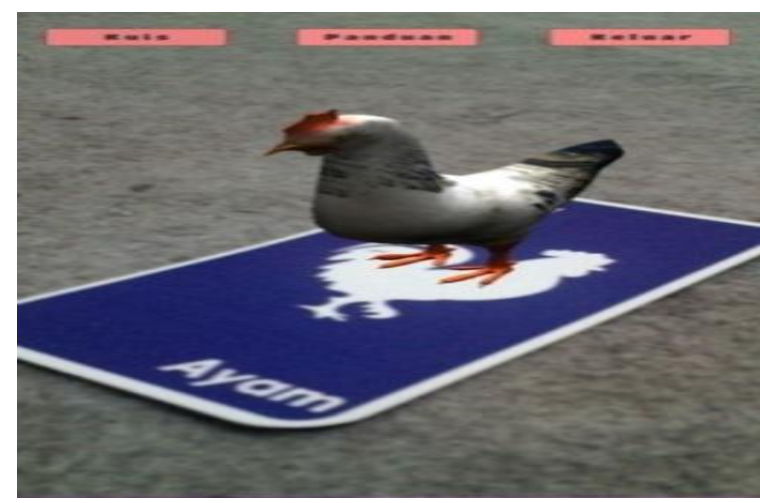

Gambar 5. Augmented Reality

\subsection{Virtual button}

Virtual button adalah button yang bisa disentuh pada lingkungan virtual. Pada sistem FCAR ini virtual button berfungsi untuk mengeluarkan suara ketika salah satu konten dari marker disentuh, dalam hal ini konten yang digunakan adalah nama obyek yang ada di flash card. Berikut langkahlangkah pembuatan virtual button.

1. MasukkanVirtual button kedalam image target yang sudah dibuat sebelumnya.

2. Siapkan suara.

3. Ubah suara menjadi 3D sound.

4. Inputkan sound ke dalam image target.

5. Buat script untuk virtual button.

6. Uji coba. 
Virtual button membutuhkan kode pemrograman untuk dapat menjalankan fungsinya. Kode bayangan dari virtual button ditunjukkan pada Gambar 6 berikut ini :

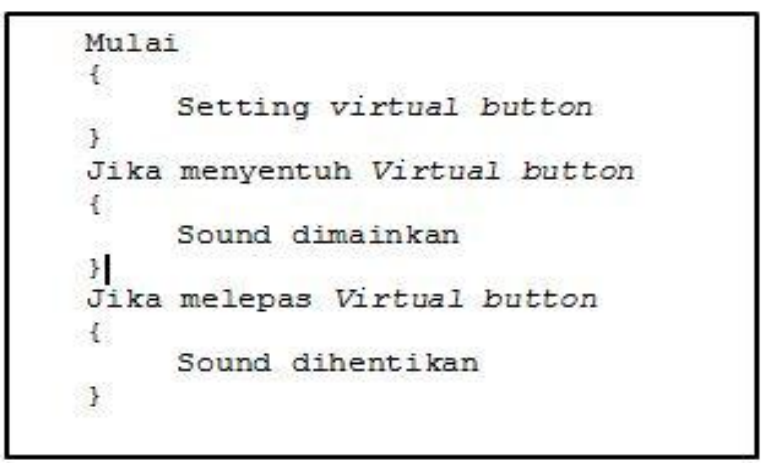

Gambar 6. Kode Bayangan Virtual Button.

AR pada bagian kuis ini berfungsi untuk memunculkan obyek sesuai dengan nama obyek yang telah dirangkai oleh anak-anak. Jika benar maka akan muncul obyek dan mengeluarkan suara yang menandakan bahwa rangkaian kata yang telah disusun benar. Jika salah maka akan keluar suara yang menandakan bahwa jawaban anak-anak salah.

\section{PEMBAHASAN}

\subsection{Motivasi Belajar}

Pada tahapan implementasi dalam kelompok belajar anak usia dini dapat dilihat bahwa anak sangat antusias untuk belajar kosakata menggunakan FCAR. Anak-anak sangat antusias karena anak-anak dapat berinteraksi dengan media FCAR pada saat belajar. Anak-anak berebut bergantian untuk mencoba menggunakan media FCAR secara mandiri.

\section{KESIMPULAN}

Sistem FCAR yang dikembangkan untuk menambah motivasi belajar anak berjalan dengan baik. Teknologi AR yang digunakan dalam sistem FCAR dapat berjalan dengan baik. Anak-anak terlihat sangat antusias dan dapat dengan mudah memahami penggunaan sistem FCAR secara mandiri.

\section{DAFTAR PUSTAKA}

Cascales, A., Lopez, D. P., Contero, M. Study on Parents Acceptance of the Augmented reality Use for Preschool Education. 2013 International Conference on Virtual and Augmented reality in Education, 2013.

Nincarean, D., Ali, M. B., Halim, N. D. A., Rahman, M. H. A. R. Mobile Augmented reality: the potential for education. $13^{\text {th }}$ International Educational Technology Conference, 2013.

Parhizkar, B., Shin, T. Y., Lahkari, A. H., Nian, Y. S. Augmented Reality Children Storybook (ARCS). 2011 International Conference on Future Information Technology, 2011.

Santana-Mancilla, P. C., Garcia-Ruiz, M. A., Acosta-Diaz, R., Juarez, C. U. Service Oriented Architecture to Support Mexician Secondary Education through Mobile Augmented reality. The $9^{\text {th }}$ International Conference on Mobile Web Information Sistems(MobiWIS), 2012.

Tezci, E. Teachers' effect on ICT use in education: The Turkey sample. Procedia-Social and Behavioral Sciences, 2009.

Zarzuela, M. M., Pernas, F. J. D., Martinez, Leire. B., Ortega, David. G., Rodriguez, Miriam. A. Mobile Serious Game using Augmented reality for Supporting Children's Learning about Animals. $2013 \quad$ International Conference on Virtual and Augmented reality in Education, 2013. 